\title{
MEMBRANE PERMEABILITY ALTERATION OF SOME BACTERIAL CLINICAL ISOLATES BY SELECTED ANTIHISTAMINICS
}

\author{
Moustafa A. El-Nakeeb, Hamida M. Abou-Shleib, Amal M. Khalil, Hoda G. Omar, Omar M. El-Halfawy *
}

Pharmaceutical Microbiology Department, Faculty of Pharmacy, Alexandria University, Egypt

Submitted: March 14, 2010; Approved: March 14, 2011.

\begin{abstract}
Several antihistaminics possess antibacterial activity against a broad spectrum of bacteria. However, the exact mechanism of such activity was unclear. Hence, the aim of this study is to investigate their mechanism of antibacterial activity especially their effect upon the permeability of the bacterial cytoplasmic membrane. The effects of azelastine, cetirizine, cyproheptadine and diphenhydramine were studied using Gram-positive and Gram-negative multiresistant clinical isolates. Leakage of 260 and $280 \mathrm{~nm} \mathrm{UV-absorbing} \mathrm{materials} \mathrm{was}$ detected upon treatment with the tested antihistaminics; indicative of membrane alteration. Using an artificial membrane model, cholesterol-free negatively-charged unilamellar liposomes, confirmed the effect of antihistaminics upon the membrane permeability both by showing an apparent membrane damage as observed microscopically and by detection of leakage of preloaded dye from the liposomes colorimatrically. Moreover, examination of the ultrastructure of cells treated with azelastine and cetirizine under the transmission electron microscope substantiated the detected abnormalities in the cell wall and membrane. Furthermore, the effect of pretreating certain isolates for both short and long periods with selected antihistaminics was followed by the viable count technique. Increased vulnerability towards further exposure to azelastine was observed in cells pretreated with azelastine for 2 days and those pretreated with azelastine or cetrizine for 30 days.
\end{abstract}

Key words: antihistaminics; azelastine; bacteria; cytoplasmic membrane; liposomes; permeability alteration.

\section{INTRODUCTION}

In preliminary studies (7), several antihistaminics belonging to different groups showed both bacteriostatic and bactericidal activities with variable magnitudes against a broad range of bacteria. However, the mechanism underlying such effects has not been clearly investigated. Speculations about their site of action could be made based upon their chemical structure. Since all antihistaminics have an amphipathic structure due to a tertiary amino group and a bulky lipophilic aromatic moiety, they possess certain surfactant-like characters $(2,4)$. Owing to the surface activity, several amphipathic compounds are reported to cause alteration in biological membranes in general (10). Two types of interactions have

*Corresponding Author. Mailing address: Pharmaceutical Microbiology Department, Faculty of Pharmacy, Alexandria University, 21521, Alexandria, Egypt.; Tel: 002-010-8145125.; E-mail: omar.alhlfawy@alexpharmacy.edu.eg 
been described for the effect of cationic amphipathic compounds on the membranes (4). The first one is the electrostatic interactions that take place between phosphate groups on the surface of the cells and the amino groups of such compounds. The second one is the hydrophobic Van der Waal interactions between the hydrophobic groups on the cell surface and the surfactant alkyl chains which penetrate the membrane bilayer. These surfactant-like cationic drugs could increase the permeability and transport across the membrane and eventually causing cytolysis $(1,4)$. Nevertheless, such speculations regarding the effect of antihistaminics upon the bacterial membranes need to be confirmed. Thus, the main aim of this study is to investigate the action of selected antihistaminics upon bacterial cytoplasmic membrane. Various techniques are applied for this purpose including transmission electron microscopy and the use of artificial membrane.

\section{MATERIALS AND METHODS}

\section{Microorganisms}

Four human bacterial isolates, identified by classical microscopical and biochemical procedures $(6,8)$, were used in this study. These are: Staphylococcus aureus $\left(\mathrm{Sa}_{103}\right)$, Enterococcus faecium $\left(\mathrm{Ef}_{101}\right)$, Escherichia coli $\left(\mathrm{Ec}_{103}\right)$ and Pseudomonas aeruginosa $\left(\mathrm{Ps}_{102}\right)$. They were maintained at $4{ }^{\circ} \mathrm{C}$ as slant cultures of sterile nutrient agar (Oxoid Ltd; Basingostok; Hampshire, England) for a maximum of one month (15).

\section{Antihistaminics}

The antihistaminics used in this study were obtained as pure dry powders of pharmaceutical grade: Azelastine hydrochloride (Aze), Cetirizine dihydrochloride (Cet), Cyproheptadine hydrochloride (Cyp) and Diphenhydramine hydrochloride (Dip). They were preserved at $4^{\circ} \mathrm{C}$. To prepare stock solutions of the antihistaminics, specified amounts of the tested antihistaminics were accurately weighed, transferred separately into suitable sterile volumetric flasks and dissolved in sterile distilled water.

Effect of antihistaminics on the cytoplasmic membrane by leakage technique

Bacterial suspensions in saline solution were developed by growing the clinical isolates on nutrient agar plates at $37^{\circ} \mathrm{C}$ for 24 hours $\left(\mathrm{OD}_{600}\right.$ adjusted to 1.5). Aliquots of the prepared suspension of each isolate were treated with $200 \mu \mathrm{g} / \mathrm{ml}$ of each of the tested antihistaminics and incubated at $37^{\circ} \mathrm{C}$ for 24 hours. A control was included in each test containing untreated bacterial suspension. Then the suspensions were centrifuged at $3,000 \mathrm{xg}$ for 10 minutes and the supernatants were passed through $0.45 \mu$ filters. The absorbance of the clear supernatant was estimated at 260 and $280 \mathrm{~nm}$ against saline solution using spectrophotometer (Thermospectronic, Helios alpha, NC 9423 UV A 1002E, England).

\section{Effect of antihistaminics on artificial cytoplasmic membrane model}

Methylene blue-loaded cholesterol-free negativelycharged unilamellar liposomes were prepared by reverse-phase evaporation method as described by Szoka and Papahadjopoulos (14). The prepared artificial cytoplasmic membrane model was characterized by morphological evaluation using light microscope (Euromed, Holland) under an oil-immersion objective lens [100 X / 1.25] in order to identify its shape and/or lamellarity and by particle size analysis for their size and size distribution using laser diffraction particle size analyzer (Cilas, 1064 liquid, France).

Aliquots of the prepared liposomal dispersion in water were treated with $200 \mu \mathrm{g} / \mathrm{ml}$ of the antihistaminics under study. Control liposomes were included in each experiment. The reaction mixtures were maintained at $4^{\circ} \mathrm{C}$ in an ice bath inside a refrigerator to eliminate any factors that might contribute to the liposomal damage other than the added drugs. Samples were withdrawn at time intervals between zero and 6 hours and 
centrifuged immediately at $10,075 \mathrm{xg}$ for $5 \mathrm{~min}$. at $4^{\circ} \mathrm{C}$ (Cooling ultracentrifuge, Sigma, Germany) and the absorbance of the leaked methylene blue in the clear supernatant was estimated using a UV-Vis spectrophotometer at $600 \mathrm{~nm}$. The readings of the control were used to correct the experimental values. In addition, 24 h-treated liposomes were examined using the optical microscope under an oil-immersion objective lens for any damage or distortion in the phospholipid bilayer. Samples were photographed using a digital camera with suitable focusing and zooming.

\section{Effect of antihistaminics on the ultrastructure of bacterial} cells using transmission electron microscope $(11,13)$

A selected clinical isolate $\left(\mathrm{Sa}_{103}\right)$ was cultivated onto nutrient agar plates containing $50 \mu \mathrm{g} / \mathrm{ml}$ of azelastine and 200 $\mu \mathrm{g} / \mathrm{ml}$ of cetirizine at $37^{\circ} \mathrm{C}$ for 48 hours. Antihistaminic-free control plates were also cultivated to obtain non-pretreated cells. The resultant bacterial growth was scraped from the plates and suspended in $10 \mathrm{ml}$ sterile saline solution. The suspensions were centrifuged at $900 \mathrm{xg}$ for 5 minutes and the sediments were washed twice with sterile saline solution. Finally, the azelastine-treated, cetirizine-treated and control bacterial pellets were then resuspended in $3 \mathrm{ml}$ Trump's solution (12), vortex mixed and centrifuged again at $900 \mathrm{xg}$ for $5 \mathrm{~min}$ to obtain fixed bacterial pellets. The pellets were then rinsed twice with $0.1 \mathrm{M}$ phosphate buffer, Post-fixed with $1 \%$ 0.2 M phosphate buffered osmium tetroxide, rinsed with phosphate buffer and dehydrated with an ethanol graded dehydration series $(25 \%$ - 100\%). The samples were infilterated with propyline oxide and embedded in epon (epoxy resin). The samples were left overnight in air for the evaporation of propyline oxide and transferred to beam capsules for polymerization in the oven until hard polymerized blocks were formed which were trimmed to trapezoid shape. Thin sections $(1-5 \mu \mathrm{m})$ were done using LKB ultra-microtome (LKB, Bromma, Sweden) and collected on mesh uncoated copper grids. Two grids were prepared for each sample. The grids were double-stained with uranyl acetate for half an hour and lead citrate for 2-3 minutes. The samples were examined and photographed at an accelerating voltage of $80 \mathrm{kV}$ using Joel CX 100 transmission electron microscope, at the Electron Microscope Unit, Faculty of Science, Alexandria University.

\section{Effect of pretreatment with selected antihistaminics on their bactericidal activity using the viable count technique}

The tested bacterial isolates were cultivated on nutrient agar plates containing $100 \mu \mathrm{g} / \mathrm{ml}$ of azelastine or cetirizine at $37^{\circ} \mathrm{C}$ for 48 hours. The resulting growth was suspended in 10 $\mathrm{ml}$ sterile saline solution. Another experiment was performed by cultivating the tested strains in $50 \mathrm{ml}$ sterile nutrient broth containing $50 \mu \mathrm{g} / \mathrm{ml}$ of the antihistaminics in sterile flasks at $37^{\circ} \mathrm{C}$ for 30 days. Antihistaminic-free control cultures were included in each test to obtain non-pretreated cells. The produced antihistaminic-pretreated and non-pretreated bacterial suspensions from each pretreatment procedure were centrifuged at 3,000 xg for 10 minutes and the remaining cells were washed twice with sterile saline solution then resuspended in $10 \mathrm{ml}$ sterile saline solution. The resultant bacterial suspensions were further treated with $100 \mu \mathrm{g} / \mathrm{ml}$ of each of the selected antihistaminics in sterile nutrient broth after being diluted to reach $\sim 10^{6} \mathrm{CFU} / \mathrm{ml}\left(\mathrm{OD}_{600} \sim 0.005\right)$. Proper controls lacking the antihistaminics were included in each test. The systems were mixed well and incubated at $37^{\circ} \mathrm{C}$. Samples were aseptically withdrawn at 0 and $24 \mathrm{hr}$. The number of viable cells was determined by the surface viable count technique.

\section{RESULTS AND DISCUSSION}

Several antihistaminics demonstrate both bacteriostatic and bactericidal activities with variable magnitudes against a broad range of bacteria as noted in preliminary studies (7). Thus, it was of importance to investigate their mechanism of antibacterial activity especially their effect upon the permeability of the bacterial cytoplasmic membrane. Four antihistaminics, namely azelastine, cetirizine, cyproheptadine 
and diphenhydramine, belonging to different groups were studied in the present investigation against 4 Gram-positive and Gram-negative multiresistant clinical isolates.

A leakage study was conducted using the antihistaminics under study by measuring spectrophotometrically the leaked 260 and $280 \mathrm{~nm} \mathrm{UV-}$ absorbing materials from the cells treated for $24 \mathrm{~h}$ as an indication of permeability alteration (Table 1). The values shown in the table represent the minimum calculated values after subtracting those due to UV absorbance of antihistaminics themselves and correction for the normal leakage from control untreated cells. Moreover, the extent of net leakage varied between the tested bacterial strains treated with the antihistaminics under study.

Table 1. Leakage of UV-absorbing materials at $260 \& 280 \mathrm{~nm}$ from test organisms cells after treatment with $200 \mu \mathrm{g} / \mathrm{ml}$ of aze, cet, dip and cyp for $24 \mathrm{~h}$ at $37^{\circ} \mathrm{C}$ in saline solution

\begin{tabular}{lccccc}
\hline \multirow{2}{*}{ Organism } & \multirow{2}{*}{$\boldsymbol{\lambda}(\mathbf{n m})$} & Aze & Cet & Dip & Cyp \\
\cline { 3 - 6 } & 260 & $0.869 \pm 0.026$ & $0.189 \pm 0.005$ & $0.766 \pm 0.038$ & $0.158 \pm 0.008$ \\
\multirow{2}{*}{$\mathrm{Sa}_{103}$} & 280 & $0.474 \pm 0.021$ & $0.277 \pm 0.014$ & $0.689 \pm 0.031$ & $-0.199 \pm 0.016$ \\
\hline \multirow{2}{*}{$\mathrm{Ef}_{101}$} & 260 & $0.832 \pm 0.049$ & $0 \pm 0.032$ & $0.878 \pm 0.070$ & $-1.176 \pm 0.112$ \\
& 280 & $0.45 \pm 0.018$ & $0 \pm 0.027$ & $0.65 \pm 0.039$ & $-1.521 \pm 0.132$ \\
\hline \multirow{2}{*}{$\mathrm{Ec}_{103}$} & 260 & $0.763 \pm 0.011$ & $0.44 \pm 0.024$ & $0.835 \pm 0.092$ & $0.946 \pm 0.142$ \\
& 280 & $-0.416 \pm 0.057$ & $0.03 \pm 0.002$ & $0.272 \pm 0.026$ & $0.085 \pm 0.007$ \\
\hline \multirow{2}{*}{$\mathrm{Ps}_{102}$} & 260 & $0.988 \pm 0.027$ & $0.834 \pm 0.066$ & $1.35 \pm 0.132$ & $0.136 \pm 0.005$ \\
& 280 & $0.444 \pm 0.013$ & $0.283 \pm 0.019$ & $1.3 \pm 0.207$ & $-0.03 \pm 0.004$ \\
\hline
\end{tabular}

T: Supernatant of treated cells measured against saline solution

AH: antihistaminic control measured against saline solution

${ }^{1}$ Represents net leakage due to antihistaminc treatment, as correction for the absorbance of supernatant of contol bacterial cells measured against saline solution was performed by subtraction, where: $A_{260}=0.240,0.154,0.115$ and $0.254 ; A_{280}=0.133,0.119,0.056$ and 0.134 in case of $\mathrm{Sa}_{103}, \mathrm{Ef}_{101}, \mathrm{Ec}_{103}$ and $\mathrm{Ps}_{102}$ control untreated cells respectively.

$*$ Results were expressed as average of 3 readings plus or minus standard deviation.

An artificial cytoplasmic membrane model was employed to support the observed permeability alterations in the bacterial cells. The membrane model was unilamellar liposomes which are cholesterol-free negatively charged phospholipids bilayer forming vesicles thus resembling the bacterial membranes. The liposomes appeared under light microscope as spherical particles, the external face of which appeared to be smooth, well-defined and upon focusing, it could be noted that they were unilamellar, i.e. composed only of 1 phospholipids bilayer. The mean diameter of the prepared liposomes was 0.94 $\mu \mathrm{m}$ and they showed a narrow size distribution. The effect of antihistaminics on the tested artificial membrane model varied in severity among the studied antihistaminics where the most obvious effects were manifested by azelastine followed by cetirizine. Diphenhydramine performed less pronounced effects whereas the weakest effect was observed in case of cyproheptadine. The effects observed under the light microscope ranged from roughness and distortion of the outline of the phospholipids membrane, to pore formation and complete rupture of the membranes as shown in Figure 2 for azelastine and cetirizine treatments. These damaging effect were substantiated by the leakage of an indicator dye that is methylene blue previously loaded into the liposomes (Figure 1). This agrees in part with the previously published effects of diphenhydramine and azelastine on monolayers of L-alphadipalmitoyl lecithin (3) and a monomolecular film of 1stearoyl-2 oleoyl-sn-glycero-3-phosphocholine $\quad(5, \quad 9)$ respectively. 


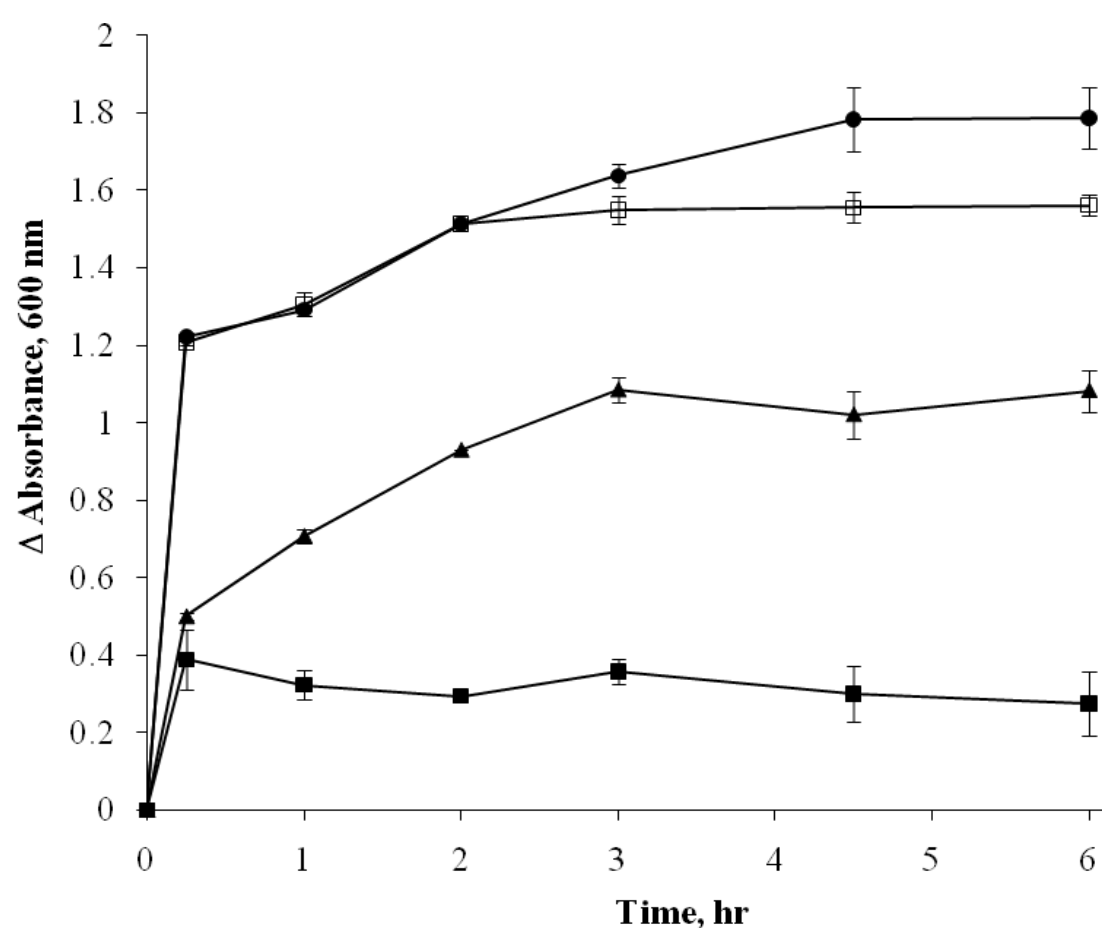

Figure 1. Effect of $200 \mu \mathrm{g} / \mathrm{ml}$ Aze $(\bullet)$, Cet ( $\square$ ), Dip ( $\mathbf{\Delta})$ and Cyp (ם) on the permeability of artificial cytoplasmic membrane model (MB-loaded negatively charged cholesterol-free unilamellar liposomes) determined by measuring the absorbance of the leaked MB.

* Results were expressed as average of 3 readings. Error bars show standard deviation.
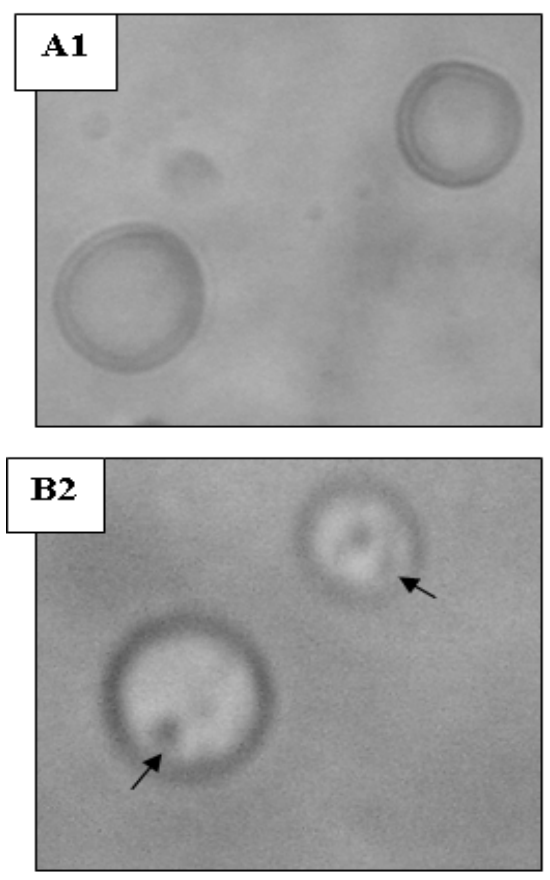
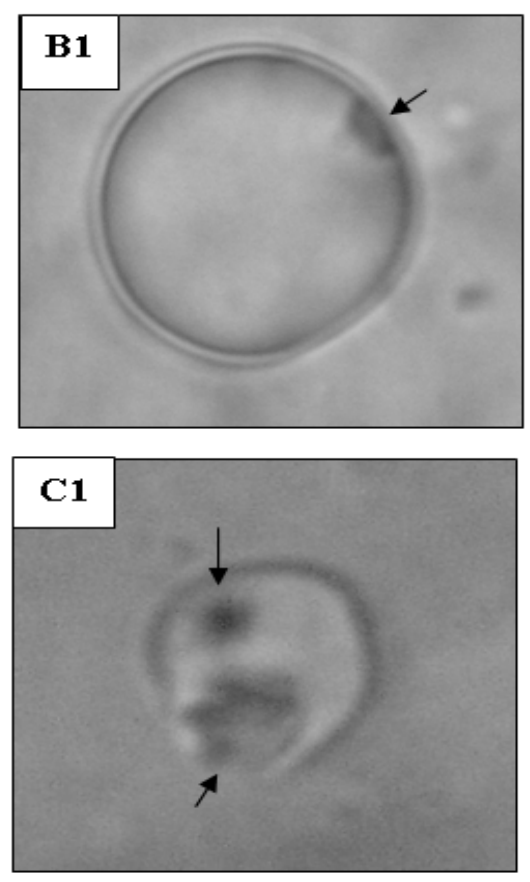

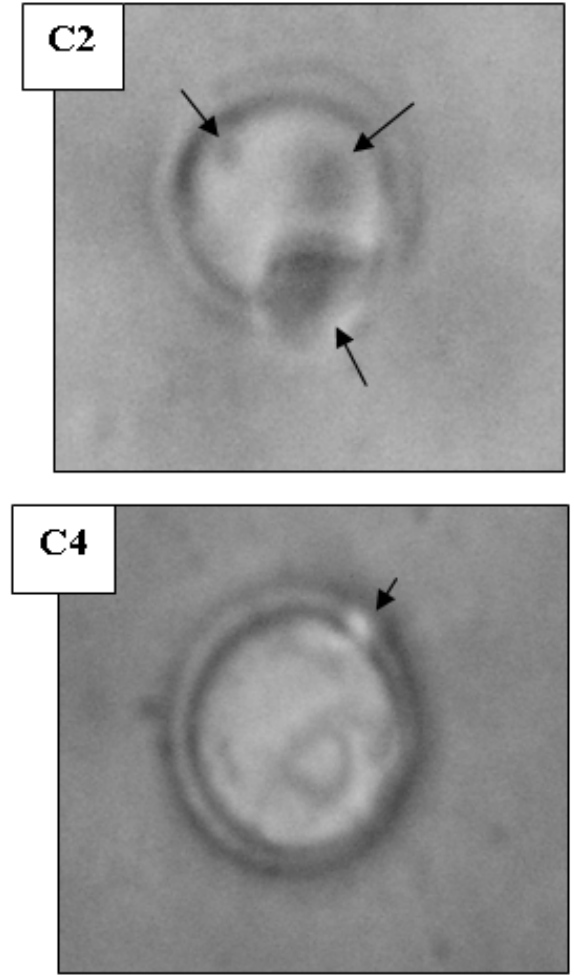
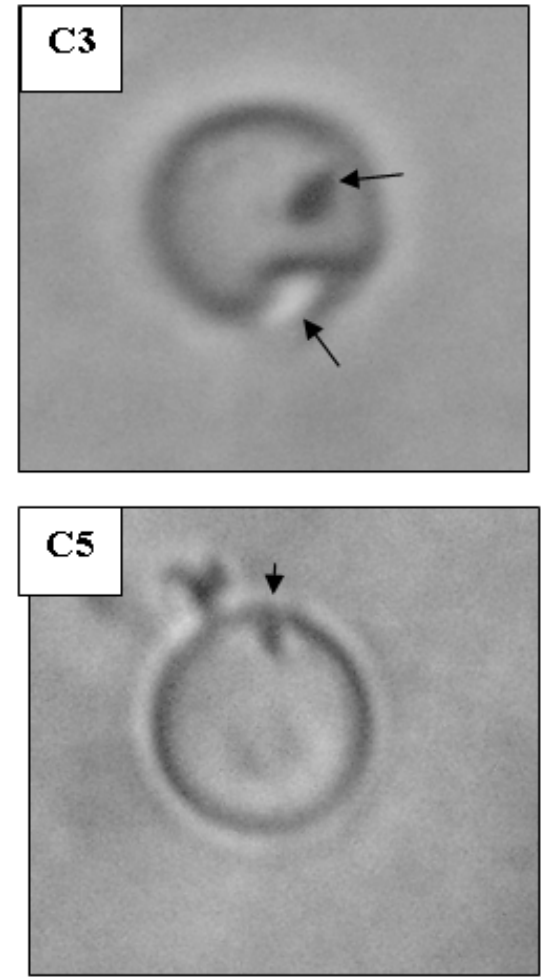

Figure 2. Morphology of liposomes examined under oil-immersion objective lens (Total magnification 1,000 X). A: untreated control, B: cetirizine-treated and C: azelastine-treated. [Additional optical zoom: (2 X) except B1 (3 X)]

Furthermore, the ultrastructure of the S. aureus $\mathrm{Sa}_{103}$ isolate treated with either azelastine or cetirizine was examined under the transmission electron microscope to reveal the possible abnormalities compared to untreated bacterial cells. A smooth continuous cell wall and cytoplasmic membrane structures were observed in the untreated bacteria. Cross wall formation was observed in several cells indicative of cell division. Cetirizine-treated cells showed enlargement and thickening of their cell walls. On the other hand, treatment with azelastine produced much more pronounced effects upon the bacterial cells. The cell walls were obviously damaged whereas the cytoplasmic membrane mostly lost its integrity compared to the control. The azelastine treated $\mathrm{Sa}_{103}$ cells also showed a cytoplasmic region that appeared to be nonhomogeneous when compared to the control. The contents of some treated cells appeared depleted in severe cases (Figure 3).
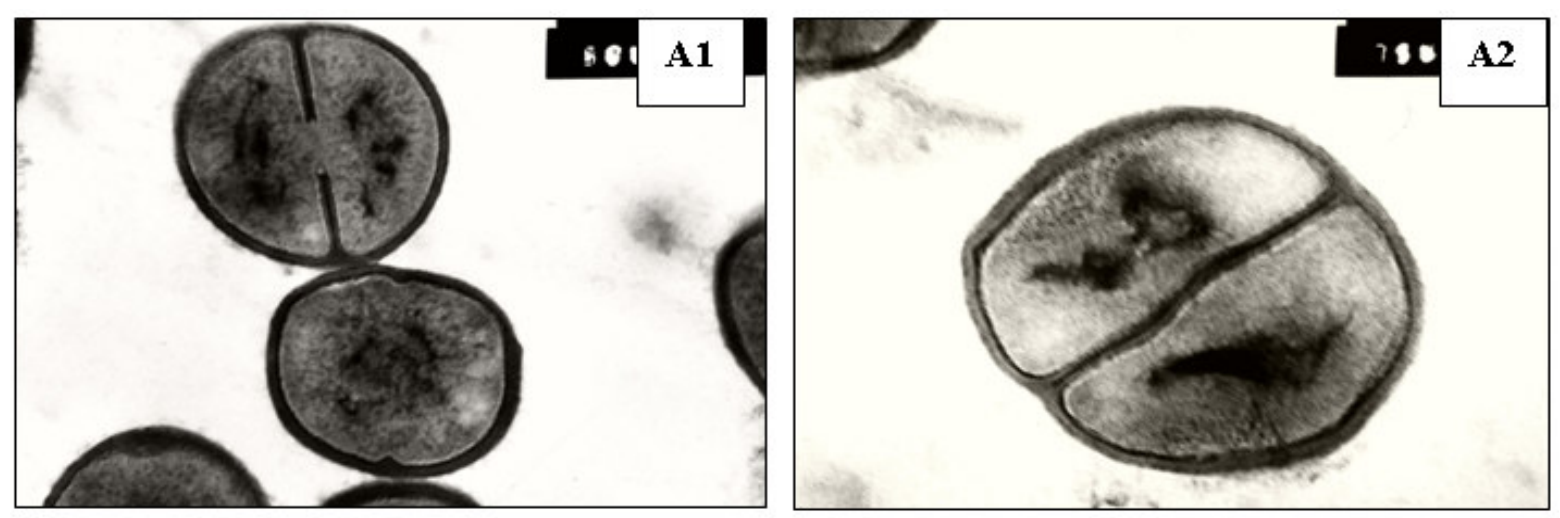

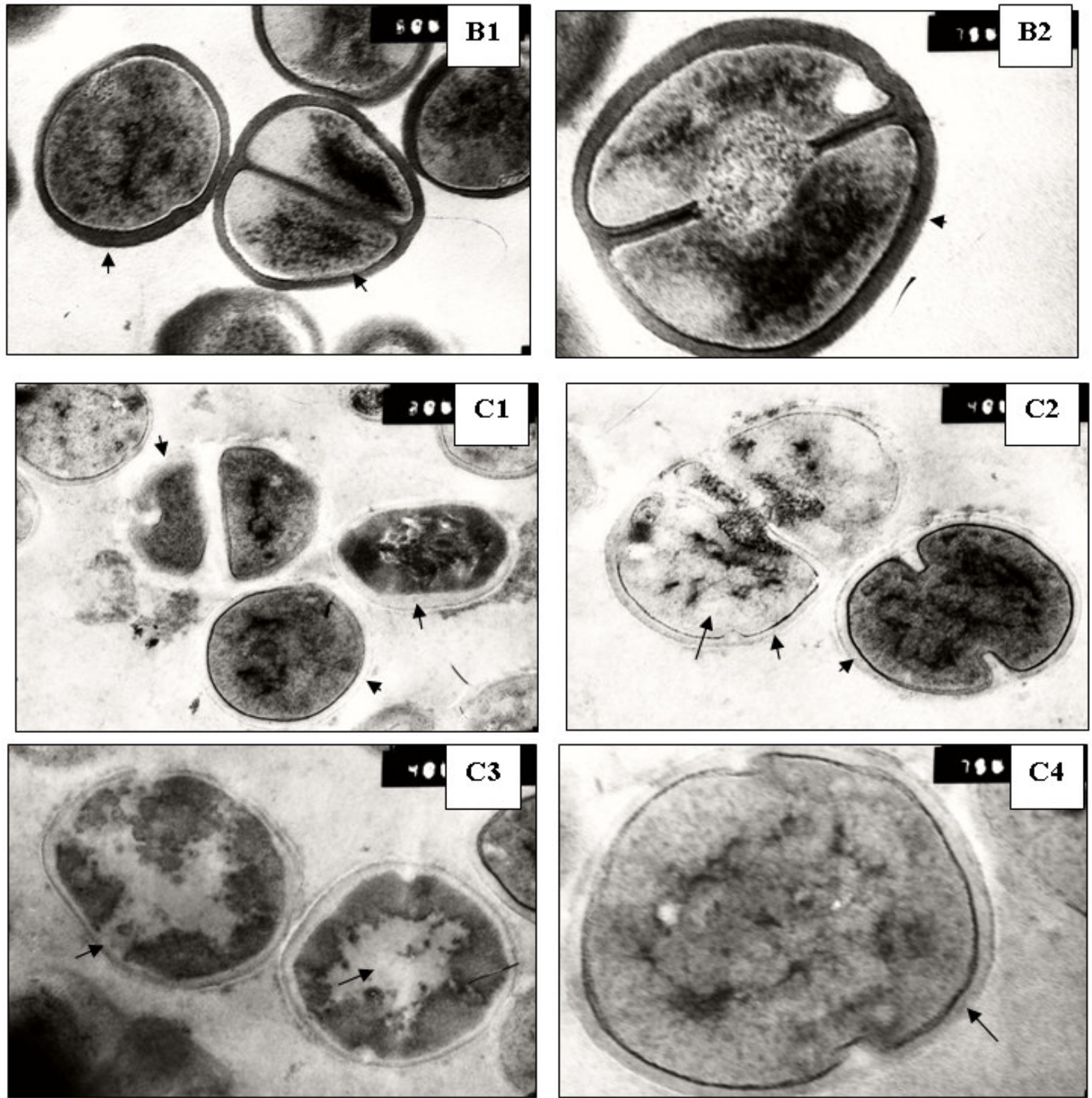

Figure 3. Ultrastructure of $S$. aureus $\mathrm{Sa}_{103}$ cells. A: control, B: cetirizine-treated cells and C: azelastine-treated cells. Magnification: 50,000X except A2, B2 and C4: 75,000X

The described membrane damage might have lead to the increased vulnerability of certain antihistaminic-pretreated cells towards further exposure to azelastine (Figure 4). The short-term and long-term pretreatment processes were designed to simulate various clinical situations in which the patients might either receive a brief course of antihistaminic treatment or be set on a long term therapy in case of chronic allergic conditions. Both 2 and 30 days azelastine pretreatment procedures of the $S$. aureus isolate caused a slight reduction in the number of viable bacteria of the control compared to the non-pretreated control. Moreover, they potentiated the effect of further azelastine treatment by further reduction in viable cells where the percentage of viable bacteria relative to the corresponding control cultures dropped from $0.014 \%$ in non- 
pretreated cultures to $0.003 \%$ in case of azelastine 2 days pretreatment and from $0.167 \%$ to $0.006 \%$ in case of 30 days pretreatment. However, they did not affect the antibacterial activity of further cetirizine treatment. On the other hand, pretreatments with cetirizine did not demonstrate detectable effects compared to the non-pretreated cells which may be due to its weaker membrane damaging effect. Nonetheless, the pretreatment with a low concentration of cetirizine for a long period of time produced a remarkable potentiation of the antibacterial activity of further treatment with $100 \mu \mathrm{g} / \mathrm{ml}$ azelastine against $S$. aureus $\mathrm{Sa}_{103}$ isolate relative to nonpretreated cells, further azelastine treatment reduced viable cells from $0.167 \%$ of the non-pretreated control culture to $0.002 \%$ of the cetrizine pretreated control.
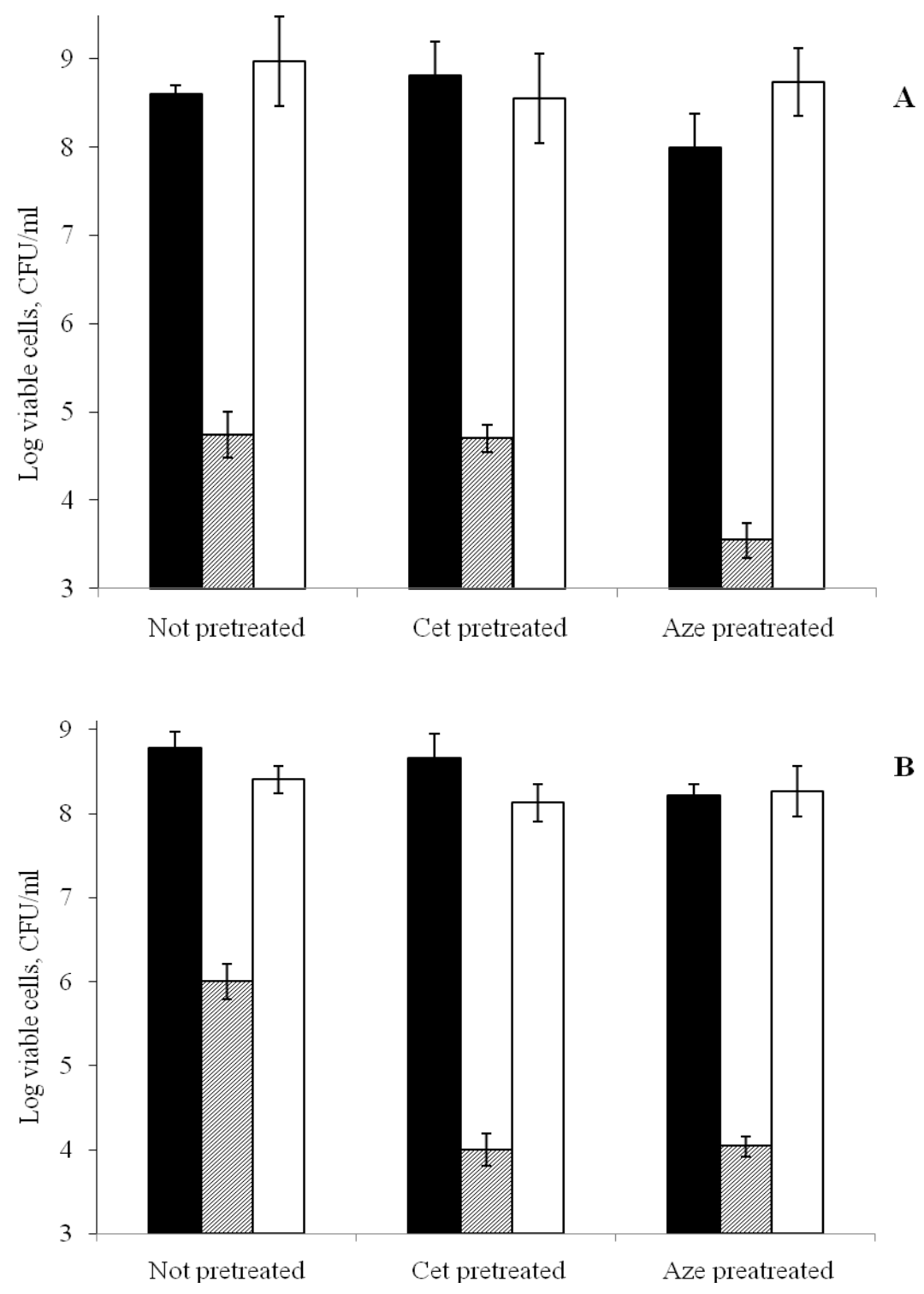

Figure 4. Effect of $48 \mathrm{hr}$ pretreatment with $100 \mu \mathrm{g} / \mathrm{ml}$ Aze \& Cet (A) and 30 days pretreatment with 50 $\mu \mathrm{g} / \mathrm{ml}$ Aze \& Cet (B) on the bactericidal action of $100 \mu \mathrm{g} / \mathrm{ml}$ Aze \& Cet against $S$. aureus $\mathrm{Sa}_{103}$ isolate determined by viable count technique at $24 \mathrm{hr}$ at $37^{\circ} \mathrm{C}$. Control (ם); Aze (j); Cet ( $\square)$.

* Results were expressed as average of 3 readings. Error bars show standard deviation. 
Therefore, it may be concluded that the alteration of membrane permeability is one of the major mechanisms underlying the antibacterial effects of antihistaminics against the tested bacteria. The variation in the magnitude of the antibacterial effects among different antihistaminics was related to their varied capacities to induce membrane damage owing to differences in their extent of adsorption onto the cell membranes as well as differences in their surface activity as previously noted (data not included). However, further studies are required to detect whether any intracellular targets for the antibacterial effects of the antihistaminics exist or not.

\section{ACKNOWLEDGEMENT}

Due thanks to Mohamed M. Mehanna (Industrial Pharmacy Department, Faculty of Pharmacy, Alexandria University) for helping in liposome preparation.

\section{REFERENCES}

1. Abernathy, C.O.; Lukacs, L.; Zimmerman, H.J. (1975). Toxicity of tricyclic antidepressants to isolated rat hepatocytes. Biochem Pharmacol 24(3), 347-50.

2. Attwood, D.; Udeala, O.K. (1974). Aggregation of antihistamines in aqueous solution: micellar properties of some diphenylmethane derivatives. J Pharm Pharmacol 26(11), 854-60.

3. Attwood, D.; Udeala, O.K. (1975). The interaction of antihistamines with lecithin monolayers. J Pharm Pharmacol 27(11), 806-10.

4. Attwood, D.; Florence, A.T. (1983). Surfactant systems: Their chemistry, pharmacy and biology. Chapman and Hall Ltd., London, p. 124-228, $388-468,607-610$
5. Brockman, H.L.; Momsen, M.M.; Knudtson, J.R.; Miller, S.T.; Graff, G.; Yanni, J.M. (2003). Interactions of olopatadine and selected antihistamines with model and natural membranes. Ocul Immunol Inflamm 11(4), 247-68.

6. Collee, J.G.; Miles, R.S. (1989). Tests for identification of bacteria. In: Collee, J.G.; Duguid, J.P.; Fraser, A.G., and Marmion, B.P. (eds). Mackie and McCartney, Practical medical microbiology. Churchill Livingstone, New York, p. 141-160.

7. El-Nakeeb, M.A.; Abou-Shleib, H.M.; Khalil, A.M.; Omar, H.G.; ElHalfawy, O.M. (2011). In vitro antibacterial activity of some antihistaminics belonging to different groups against multi-drug resistant clinical isolates. Braz. J. Microbiol. 42 (3).

8. Finegold, S.M.; Baron, E.J., eds (1986). Bailey and Scott's Diagnostic Microbiology. The C. V. Mosby company, St. Louis, p. 70-125, 173-201, $355-387,397-437,859-914$

9. Graff, G.; Miller, S.T.; Yanni, J.M.; Momsen, M.M.; Brockman, H.L. ( 2004). The effects of olopatadine, desloratadine, ketotifen, azelastine, and epinastine on membrane stability. Journal of Allergy and Clinical Immunology 113(2, Supplement 1), S328.

10. Guth, P.S.; Spirtes, M.A. (1964). The Phenothiazine tranquilizers: Biochemical and Biophysical Actions. Int Rev Neurobiol 7, 231-78.

11. Kim, Y.; Farrah, S.; Baney, R.H. (2007). Membrane damage of bacteria by silanols treatment. Electronic Journal of Biotechnology 10 (2), 252259.

12. McDowell, E.M.; Trump, B.F. (1976). Histologic fixatives suitable for diagnostic light and electron microscopy. Arch Pathol Lab Med 100(8), 405-14.

13. Suganuma, A. (1966). Further studies on the plasma membrane of Staphylococcus aureus. J Cell Biol 30(1), 208-10.

14. Szoka, F., Jr.; Papahadjopoulos, D. (1978). Procedure for preparation of liposomes with large internal aqueous space and high capture by reversephase evaporation. Proc Natl Acad Sci U S A 75(9), 4194-8.

15. Vandepitt, J.; Engbaek, K.; Piot, P.; Heuck, C.C. (1991). Basic Laboratory Procedures in Clinical Bacteriology. World Health Organization, Geneva, p. 13-15. 